\title{
COMPRESSION BEHAVIOUR OF PA2200 LATTICE STRUCTURES
}

\author{
Nichita-Larisa Milodin ${ }^{1}$, Nicoleta-Mirela Popa ${ }^{1,2}$, Mihai Tutoveanu ${ }^{1,2}$ and Flavia-Petruța-Georgiana Artimon ${ }^{1,2}$ \\ ${ }^{1}$ National Institute of Research and Development in Mechatronics and Measurement Technique (INCDMTM), \\ 021612 Bucharest, Romania \\ ${ }^{2}$ University Politehnica of Bucharest, 060042 Bucharest, Romania \\ Emails: nichita.milodin@incdmtm.ro, nicoleta.popa@incdmtm.ro, mihai.tutoveanu@incdmtm.ro
}

\begin{abstract}
This paper is aimed at studying lattice structures for medical applications. This concerns all steps from the design phase, which includes geometry optimization through finite element analysis, fabrication through additive manufacturing, part quality control and mechanical testing at compression. The experimental planning includes several variation factors, from design (such as geometry or dimension of key parameters) to additive manufacturing (such as the thickness of the manufacturing layer). Five specimens of each topology (diamond, octet-truss and cube, with 5 and $10 \mathrm{~mm}$ for the strut diameter and $60-70 \%$ porosity) were manufactured with 0,06 and $0,1 \mathrm{~mm}$ printing layers. A difference between the additive manufacturing processes was determined after measuring 30 of the fabricated specimens. Compressive testing showed different behaviour for each geometry.
\end{abstract}

Keywords: Selective-laser-sintering, Lattice Structures, Compressive Testing, Additive Manufacturing, E-Modulus.

\section{Introduction}

Selective laser sintering (SLS) is an additive manufacturing process which allows to fabricate complex structures otherwise difficult, expensive or wasteful to achieve by classical processing methods. $[1,2]$.

This represents a substantial advantage for a numerous domains. The characteristic of adding each layer of material and exposing it with the laser is useful:

- for the medical field, where customized implants are needed and can be achieved because the medical images are also obtained by layers [3], the complex structures can lower the weight [4], and it improves the cell adhesion when implanted [5] while maintaining the needed mechanical properties [6-7];

- in industrial applications, for small or medium batch series productions of tools for the injection molding process [8].

The porous design of lattice structures, integrated in different applications, can offer lightweight and control of elasticity/flexibility. Those advantages are pressing needs in many areas such as medical, aero-spatial or automotive industry. Selective laser sintering (SLS) is a highly versatile additive manufacturing (AM) technology which is best applicable to semi-crystalline polymers like the mostly used polyamides such as PA2200 [9]. However manufacturers and researchers are constantly trying to maintain or to improve the quality of new products by increasing their resistance to various mechanical, dynamic stress, at the same time minimizing their weight and dimensions [2].

A method for optimizing lattice structures was approached in previous research. The design was planned with three geometrical shapes for a cellular unit of the lattice. The porosity was alternated by modifying two key dimensions. The specimens were digitally tested by finite element analysis (FEA) at a compression load of $2400 \mathrm{~N}$. The simulation concluded that the octet-truss design has better performances than other geometries for the manufacturing material of cobalt-chrome powder.

Various experimental studies present the results of different cellular network structures effects on the strength of additive-manufactured parts, by different methods: compression tests applied to specimens [10], finite element analysis [11], microstructure analysis by using scanning electron microscopy [12]. But most of the work has been conducted with metal parts, manufactured using DMLS. The mechanical strength of polymer AM parts has been investigated less often [2].

Our research aimed to determine the mechanical characteristics of structures with complex geometries. They were additive manufactured of polyamide so as to decide if they are suitable for future applications before manufacturing them from metals, which is an expensive and longer process, thus lowering the general costs of the manufacturing lattice structures. 
The prior conducted research on this matter suggested that the lattice structures, integrated in customized implants, provide enough strength and elasticity in order to behave under normal conditions, and have the advantage of having a smaller weight.

Following, several specimens of lattice structures have been manufactured in order to subject them to mechanical stresses, to determine their behavior, the technical characteristic of SLS manufactured probes, and to verify if the process of selective laser sintering is appropriate for such structures.

\section{Experimental Planning}

In order to establish the material characteristics, the lattice structures cell types were chosen, fabricated by SLS 3D printing technology from PA2200 Powder material, and subjected to compression with a $10 \mathrm{kN}$ loading force cell. Experimental conditions, variables and premises were wittingly chosen, hence various aspects were stated as follows:

- Specimens' design:

- Various specimens and cell geometries were determined and so considered the independent variables;

- At least three different types of structural specimens were tested;

- At least two structural dimensions were tested

- The specimens' porosity is between $60 \%$ and $70 \%$, and it was considered the control variable;

- The specimens' height and the strut diameter are the dependent variables and were determined based on the specimens' porosity.

The FEM analyses conducted in the specialty literature [13] concludes that the octet cellular unit has the leading results.

- Specimens' SLS fabrication [14]:

- The printing layer's thickness is considered the independent variable;

- At least two process parameters were taken into consideration.

As yet, it is considered that the smaller the thickness layer, the better the material strength. Also, the layer thickness might also influence the specimens' height.

- Testing conditions:

- Design and manufacturing parameters conditions are chosen according to an international standard testing method.

The compression tests were conducted in agreement with EN ISO 604:2008 and SR EN ISO 291:2008. Some of the design characteristics were determined with respect to ISO 13314:2011 such that, further studies will be performed with the same sample structures but with a different material $(\mathrm{CoCr}$ powder).

\section{Designing the Structures}

For the ensuring of these conditions, there have been designed several types of lattice structures, with different geometries, topologies and dimensions. As it was mentioned above, by following the same process used in previous research on $\mathrm{CoCr}$ additive manufactured lattice structures, the unitcells were multiplied to obtain the test specimens [14]. After that, each structure was simulated at compression tests by the FEM analysis and only the ones that had the minimal required strength were proposed to be produced by the additive manufacturing process.

In figure 1 it can be observed a cellular unit, for each of the geometries, and the annotation used for the experimental planning; where $L_{c}$ is the length of the cellular unit and $D_{S}$ is the diameter of the strut. For the whole structure, the height is abbreviated with Hs.
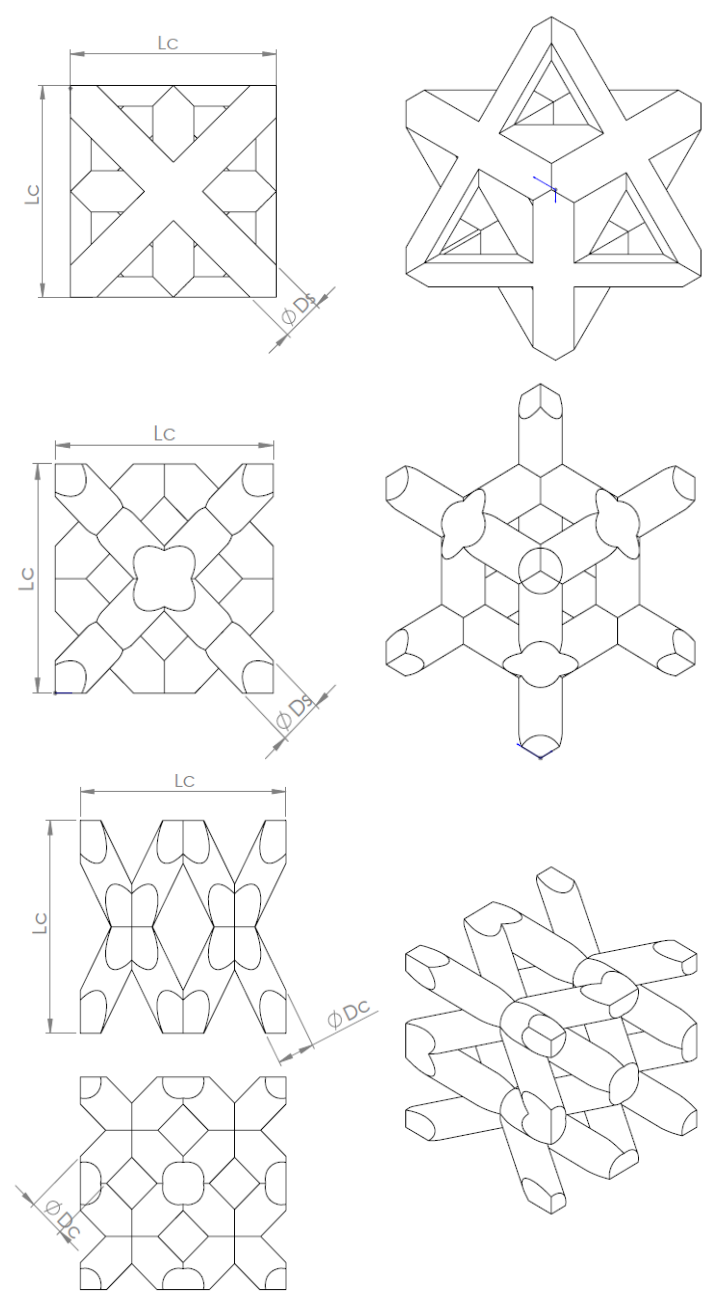

Figure 1. Annotation of design parameters for octet, diamond and cube cellular unit 
Considered adequate for this experiment were three geometry types: diamond, octet and cube, but also two sizes of unit-cell-length: 5 and $10 \mathrm{~mm}$.

Depending on this aspect, the strut diameters were calculated, for each geometry, to maintain constant the porosity of the specimens. As a result, the diameter of the struts slightly varies depending on the geometry. The final specimens have the same base area $(20 \times 20 \mathrm{~mm})$ but different heights, HS $=25$ $\mathrm{mm}$ for the unit-cells with $\mathrm{LC}=5 \mathrm{~mm}$ and $\mathrm{HS}=30 \mathrm{~mm}$ for the unit-cells with $\mathrm{LC}=10 \mathrm{~mm}$.

All the design parameters mentioned can be found in Table 1.

Table 1. Design and process parameters

\begin{tabular}{|c|c|c|c|c|c|c|}
\hline \multicolumn{7}{|c|}{ Design Parameters } \\
\hline Geometry & \multicolumn{2}{|c|}{ DIAMOND } & \multicolumn{2}{|c|}{ OCTET } & \multicolumn{2}{|c|}{ CUBE } \\
\hline $\mathrm{Lc}_{\mathrm{c}}[\mathrm{mm}]$ & 5 & 10 & 5 & 10 & 5 & 10 \\
\hline $\mathrm{D}_{\mathrm{s}}[\mathrm{mm}]$ & 0.90 & 1.90 & 0.80 & 1.70 & 0.75 & 1.60 \\
\hline $\mathrm{H}_{\mathrm{s}}[\mathrm{mm}]$ & 25 & 30 & 25 & 30 & 25 & 30 \\
\hline $\mathrm{P}[\%]$ & 67.79 & 64.37 & 68.40 & 64.53 & 68.05 & 64.00 \\
\hline $\mathrm{P} ?$ & Yes & Yes & Yes & Yes & Yes & Yes \\
\hline \multicolumn{7}{|c|}{ Process Parameters } \\
\hline \multirow{2}{*}{$\begin{array}{c}\text { Layer Thickness } \\
{[\mathrm{mm}]}\end{array}$} & 0.10 & 0.10 & 0.10 & 0.10 & 0.10 & 0.10 \\
\hline & 0.06 & 0.06 & 0.06 & 0.06 & 0.06 & 0.06 \\
\hline
\end{tabular}

The experimental condition of the porosity is verified in Table 1, under the "P?" sign. The porosity of each design is calculated using, for example, the equation (1), where VL is of the lattice structures, calculated with the digital CAD software and Vs the volume of a solid structure with the same overall dimension.

$$
\text { Porosity }=\left(1-\frac{V_{1}}{V_{s}}\right) * 100[\%]
$$

After verifying that all the structures have a porosity of $60-70 \%$, a bottom and an upper rigid plate are added to the specimens for better results during the compression tests.

\section{Additive Specimens \\ Manufacturing}

the

As suggested in ISO 13314, at least 5 specimens have to be tested for each type of structure. Therefore, 60 specimens were manufactured, post processed and tested. Details as orientation in the printing volume and specimen labels can be seen in figure 2 .

The specimens were labeled according to the rule: Geometry_Lc_Ds.

The printing processes were divided in two, based on the cellular length, and each dimension was fabricated with two different printing profiles.

The layer thicknesses were chosen conforming with the SLS machine's specific printing profiles: Performance $(\mathrm{P})$, with a $0,1 \mathrm{~mm}$ layer thickness, and Top-Quality (TQ), with a 0,06 mm layer thickness, as seen in Table 1.
The plastic powder used is a compound of PA12, preprocessed according to the requirements of each profile. An exposure temperature of $169^{\circ} \mathrm{C}$ was used for fabrication.

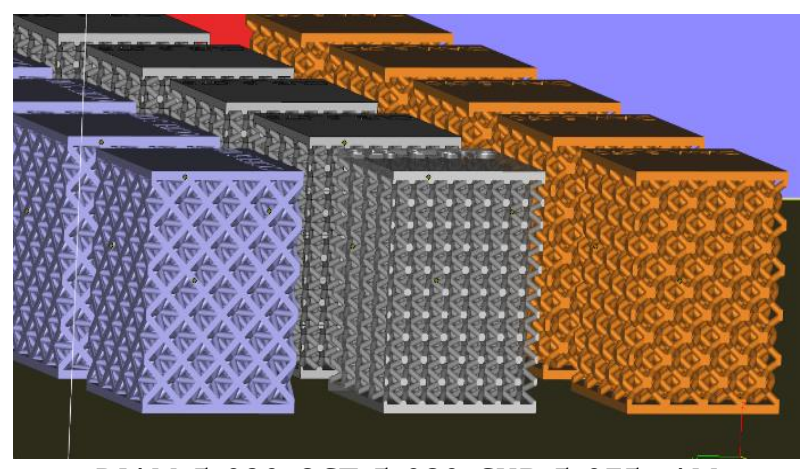

DIAM_5_090,0CT_5_080,CUB_5_075 - AM

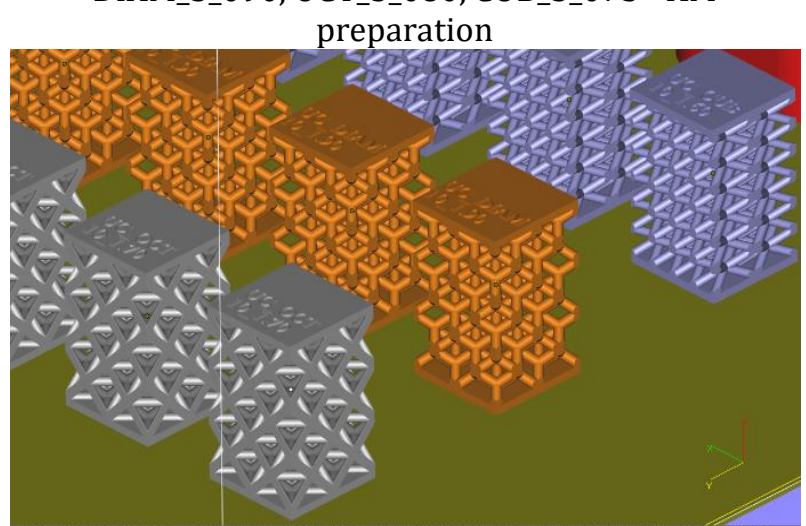

DIAM_10_1.90,OCT_10_1.70,CUB_10_1.60 - AM preparation

Figure 2. AM preparation for Lattice structures 
Unexpectedly, the TQ octet structures with cellular length of $5 \mathrm{~mm}$ failed during the printing process. Therefore, they were removed from the process and the fabrication continued without them. Some of the failure sources might have been the usage of a high percentage of recycled powder, which influences the printing temperature, and the $\mathrm{Z}$ orientation of the structures in the building volume [15].

This event determined the refabrication of these structures. In order to avoid a new failure, the orientation in the building volume was changed but this detail might have had and influence over the compression tests results as it may be seen further.
The tensile properties are direction-dependent, as some studies approves [14].

\section{Measurement}

After post-processing, the structures were measured using the recommendation mentions in the EN ISO 604:2008 plastics standard.

In figure 3 , it can be seen the dimension of the designed structures with the $10 \mathrm{~mm}$ cell and the annotation for the measured parameters.

Each measured parameters can be seen in table 2 and compared with the dimension used for designing.
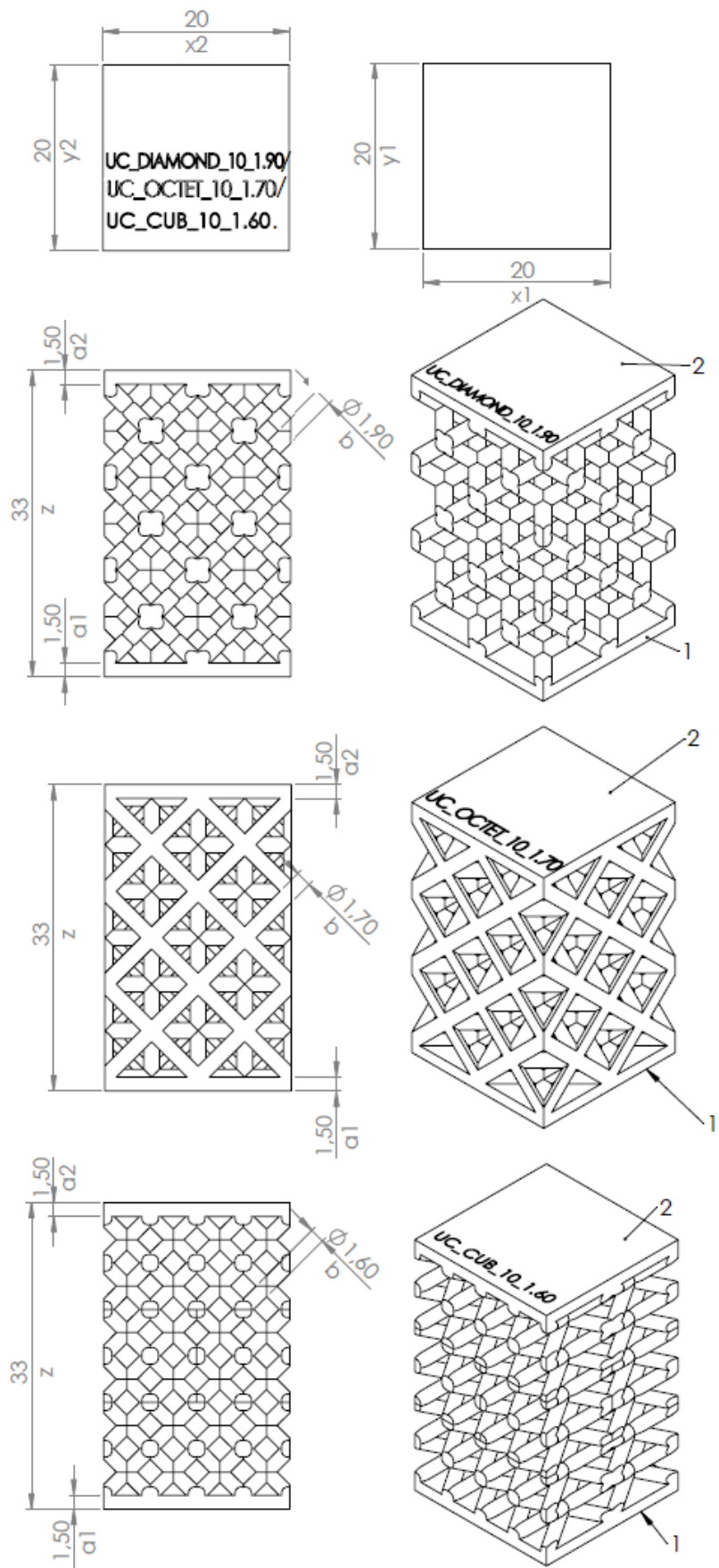

Figure 3. Annotation of measured parameters for octet, diamond and cube cellular unit 
The measurements were made in three different points, using a digital caliper with a dimension accuracy of \pm $0.02 \mathrm{~mm}$.

Table 2 Measurement of specimens with $10 \mathrm{~mm}$ strut diameter, for both the $P$ and TQ processes

\begin{tabular}{|c|c|c|c|c|c|c|c|c|}
\hline \multicolumn{2}{|c|}{ Specimen } & $\mathbf{z}$ & a1 & a2 & $\mathbf{X 1}$ & $\mathbf{x}_{2}$ & $\mathbf{y}_{1}$ & $\mathbf{y}_{2}$ \\
\hline \multicolumn{9}{|c|}{ I. Performance $(0.10 \mathrm{~mm})$} \\
\hline \multirow{4}{*}{ 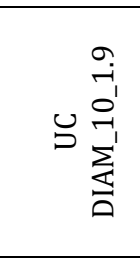 } & 1 & 33.06 & 1.56 & 1.62 & 19.84 & 20.00 & 19.84 & 19.91 \\
\hline & 2 & 33.10 & 1.59 & 1.65 & 20.00 & 19.85 & 19.85 & 20.00 \\
\hline & 3 & 33.17 & 1.58 & 1.64 & 19.9 & 20.00 & 20.00 & 19.94 \\
\hline & 4 & 33.11 & 1.56 & 1.62 & 20.00 & 20.00 & 19.85 & 19.87 \\
\hline \multirow{4}{*}{ 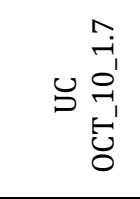 } & 1 & 33.16 & 1.56 & 1.62 & 19.98 & 19.99 & 20.00 & 19.94 \\
\hline & 2 & 33.15 & 1.58 & 1.63 & 19.91 & 20.00 & 19.96 & 19.93 \\
\hline & 3 & 33.10 & 1.58 & 1.63 & 19.96 & 19.98 & 19.94 & 19.97 \\
\hline & 4 & 33.11 & 1.58 & 1.64 & 19.93 & 19.98 & 19.99 & 19.93 \\
\hline \multirow{4}{*}{ مِ } & 1 & 33.25 & 1.57 & 1.58 & 19.82 & 19.93 & 19.86 & 19.96 \\
\hline & 2 & 33.26 & 1.57 & 1.54 & 19.95 & 19.86 & 19.73 & 19.88 \\
\hline & 3 & 33.25 & 1.52 & 1.55 & 19.81 & 19.92 & 19.83 & 19.92 \\
\hline & 4 & 33.17 & 1.49 & 1.55 & 19.80 & 19.86 & 19.82 & 19.93 \\
\hline & & & & & & & & \\
\hline & & & & & & & & \\
\hline \multicolumn{9}{|c|}{ II. Top Quality (0.06 mm) } \\
\hline \multirow{4}{*}{ 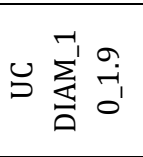 } & 1 & 33.76 & 1.84 & 1.74 & 19.86 & 20 & 19.87 & 19.93 \\
\hline & 2 & 33.78 & 1.84 & 1.63 & 19.84 & 20 & 19.83 & 19.90 \\
\hline & 3 & 33.73 & 1.84 & 1.72 & 19.79 & 19.84 & 19.81 & 19.88 \\
\hline & 4 & 33.74 & 1.84 & 1.72 & 19.82 & 19.99 & 19.84 & 19.92 \\
\hline \multirow{4}{*}{ 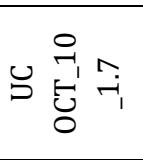 } & 1 & 33.72 & 1.81 & 1.73 & 19.81 & 19.94 & 19.85 & 19.88 \\
\hline & 2 & 33.77 & 1.80 & 1.67 & 19.78 & 19.96 & 19.84 & 19.87 \\
\hline & 3 & 33.72 & 1.82 & 1.71 & 19.81 & 20.02 & 19.84 & 19.92 \\
\hline & 4 & 33.78 & 1.83 & 1.67 & 19.92 & 20.01 & 19.88 & 20.03 \\
\hline \multirow{4}{*}{ مُ } & 1 & 33.78 & 1.87 & 1.67 & 20.03 & 20.03 & 19.89 & 19.93 \\
\hline & 2 & 33.64 & 1.88 & 1.70 & 19.91 & 19.99 & 19.88 & 19.96 \\
\hline & 3 & 33.76 & 1.82 & 1.69 & 19.91 & 20 & 19.91 & 19.95 \\
\hline & 4 & 34.11 & 1.74 & 1.62 & 19.86 & 19.92 & 19.87 & 19.86 \\
\hline
\end{tabular}

It can be observed that the affected dimensions, for both the $\mathrm{P}$ and TQ processes, are the ones built in the $\mathrm{Z}$ direction. The $\mathrm{x}_{1}, \mathrm{x}_{2}, \mathrm{y}_{1}, \mathrm{y}_{2}$ have close values to the theoretic ones, but the $\mathrm{z}, \mathrm{a}_{1}$ and $\mathrm{a}_{2}$ present bigger dimensions variations.

\section{Compression Testing}

The compression tests were conducted on a universal testing machine (HOUNSFIELD 10KT), using a $10 \mathrm{kN}$ load cell. The Young's Modulus and the displacement at the maximum force were measured. The overall strain-stress was measured based on the displacement of the testing machine.

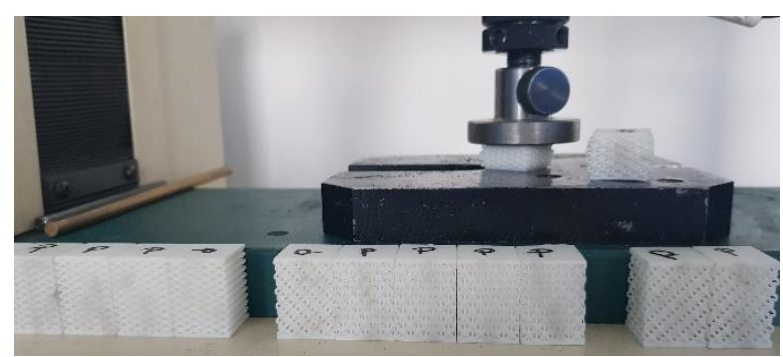

Figure 4. The HOUNSFIELD 10KT equipment and the visual difference between already compressed structure and structures prepared for compression

The tests were performed in accordance with the SR EN ISO 604:2003. standard of compression. Five specimens of each structure were tested, using the machine settings: speed $1.3 \mathrm{~mm} / \mathrm{min}$, maximum load force $10 \mathrm{kN}$ and a preload of $100 \mathrm{~N}$. The specimens were labeled for the compression: geometry. profile (P-performance/TQ-top quality). cell length(b$10 \mathrm{~mm} / \mathrm{s}-5 \mathrm{~mm})$. 
The resulted e-modulus for all the specimens, the mean value and the standard deviation are presented in Table3.

Table 3. E-Modulus and maximum force results at the compression testing, with mean and standard

\begin{tabular}{|c|c|c|}
\hline Specimen & $\begin{array}{l}\text { E-Modulus } \\
\text { [MPa] }\end{array}$ & $\begin{array}{l}\text { Compression at maximum } \\
\text { force [mm] }\end{array}$ \\
\hline DIAM P.B.1 & 12.23 & 21.80 \\
\hline DIAM P.B.2 & 12.04 & 21.80 \\
\hline DIAM P.B.3 & 11.96 & 21.60 \\
\hline DIAM P.B.4 & 12.05 & 22 \\
\hline DIAM P.B.5 & 9.27 & 20.4 \\
\hline Mean value & 11.6285 & 21.52 \\
\hline Stand. dev. & 0.9880 & 0.64 \\
\hline OCT P.B.6 & 8.90 & 23.10 \\
\hline OCT P.B.7 & 6.59 & 22.80 \\
\hline OCT P.B.8 & 8.47 & 22.80 \\
\hline OCT P.B.9 & 7.70 & 23.20 \\
\hline OCT P.B.10 & 4.76 & 21.40 \\
\hline Mean value & 7.2830 & 22.66 \\
\hline Stand. dev. & 1.6616 & 0.72 \\
\hline CUB P.B.11 & 7.35 & 24.20 \\
\hline CUB P.B.12 & 7.12 & 24.00 \\
\hline CUB P.B.13 & 7.27 & 23.80 \\
\hline CUB P.B.14 & 7.01 & 23.80 \\
\hline CUB P.B.15 & 6.71 & 22.80 \\
\hline Mean value & 7.0907 & 23.72 \\
\hline Stand. dev. & 0.2503 & 0.54 \\
\hline DIAM P.S.1 & 10.97 & 18.18 \\
\hline DIAM P.S.2 & 10.84 & 18.08 \\
\hline DIAM P.S.3 & 10.90 & 18.28 \\
\hline DIAM P.S.4 & 11.27 & 18.18 \\
\hline DIAM P.S.5 & 10.89 & 18.18 \\
\hline Mean value & 10.9739 & 18.18 \\
\hline Stand. dev. & 0.1735 & 0.07 \\
\hline OCT P.S.6 & 3.97 & 18.28 \\
\hline OCT P.S.7 & 2.13 & 18.68 \\
\hline OCT P.S.8 & 4.09 & 18.08 \\
\hline OCT P.S.9 & 1.66 & 18.68 \\
\hline OCT P.S.10 & 5.33 & 17.94 \\
\hline Mean value & 3.4358 & 18.33 \\
\hline Stand. dev. & 1.5148 & 0.34 \\
\hline CUB P.S.11 & 51.13 & 19.78 \\
\hline CUB P.S.12 & 48.56 & 19.68 \\
\hline CUB P.B.13 & 49.72 & 19.78 \\
\hline CUB P.S.14 & 40.71 & 19.78 \\
\hline CUB P.S.15 & 52.97 & 19.88 \\
\hline Mean value & 48.6197 & 19.78 \\
\hline Stand. dev. & 4.7157 & 0.07 \\
\hline DIAM TQ.B.1 & 13.99 & 21.80 \\
\hline DIAM TQ.B.2 & 13.86 & 21.80 \\
\hline DIAM TQ.B.3 & 12.41 & 22.20 \\
\hline DIAM TQ.B.4 & 14.40 & 21.60 \\
\hline
\end{tabular}




\begin{tabular}{|c|c|c|}
\hline DIAM TQ.B.5 & 10.52 & 19.80 \\
\hline Mean value & 13.0365 & 21.44 \\
\hline Stand. dev. & 1.5941 & 0.94 \\
\hline OCT TQ.B.6 & 8.46 & 22.90 \\
\hline OCT TQ.B.7 & 9.93 & 22.60 \\
\hline OCT TQ.B.8 & 10.63 & 22.70 \\
\hline OCT TQ.B.9 & 10.44 & 22.70 \\
\hline OCT TQ.B.10 & 8.72 & 21.90 \\
\hline Mean value & 9.6349 & 22.56 \\
\hline Stand. dev. & 0.9927 & 0.38 \\
\hline CUB TQ.B.11 & 8.28 & 23.50 \\
\hline CUB TQ.B.12 & 9.49 & 24.00 \\
\hline CUB TQ.B.13 & 8.55 & 23.60 \\
\hline CUB TQ.B.14 & 8.20 & 23.40 \\
\hline CUB TQ.B.15 & 6.60 & 22.40 \\
\hline Mean value & 8.2251 & 23.38 \\
\hline Stand. Dev. & 1.0420 & 0.59 \\
\hline DIAM TQ.S.1 & 22.43 & 15.10 \\
\hline DIAM TQ.S.2 & 32.13 & 14.20 \\
\hline DIAM TQ.S.3 & 29.87 & 14.50 \\
\hline DIAM TQ.S.4 & 31.14 & 14.59 \\
\hline DIAM TQ.S.5 & 30.79 & 14.80 \\
\hline Mean value & 29.2479 & 14.64 \\
\hline Stand. dev. & 3.9121 & 0.34 \\
\hline OCT TQ.S.6 & 12.28 & 14.20 \\
\hline OCT TQ.S.7 & 14.35 & 14.80 \\
\hline OCT TQ.S.8 & 13.43 & 14.10 \\
\hline OCT TQ.S.9 & 12.42 & 14.50 \\
\hline OCT TQ.S.10 & 13.36 & 14.40 \\
\hline Mean value & 13.1680 & 14.40 \\
\hline Stand. dev. & 0.8442 & 0.28 \\
\hline CUB TQ.S.11 & 6.61 & 22.60 \\
\hline CUB TQ.S.12 & 5.96 & 22.80 \\
\hline CUB TQ.S.13 & 5.88 & 22.10 \\
\hline CUB TQ.S.14 & 5.92 & 22.00 \\
\hline CUB TQ.S.15 & 5.46 & 21.80 \\
\hline Mean value & 5.9659 & 22.26 \\
\hline Stand. dev. & 0.4131 & 0.42 \\
\hline
\end{tabular}

The specimens' behavior can be analyzed in Figure. 4. It can be noticed that the results dispersion is good which might lead to a highly repeatable process. Even though three different types of structures were tested, their Force-Extension characteristics were differentiated in two ways:

- For the diamond and octet structures, the Force-Extension curves have similar behavior. There is presented an elastic deformation zone, in which each strut is buckling, caused by the fact that the struts of the cellular units for these structures are not on the same direction with the loading Force.
For the TQ processed structures, there are observed slightly better elastic properties than for the $\mathrm{P}$ ones.

- The cube lattice structured specimens reach their elastic limits at around $10 \mathrm{~mm}$ determining a much longer elastic slope than the other two. The cube has a structure that could lead to buckling, which did not happen according to the curve representation. This fact confirms the suspicion that the cubic structures have a stiffer behavior in comparison to the other ones. 


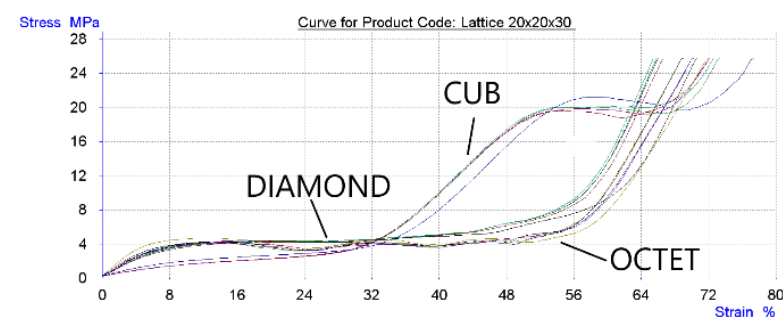

a.Performance lattices with $10 \mathrm{~mm}$ cellular length

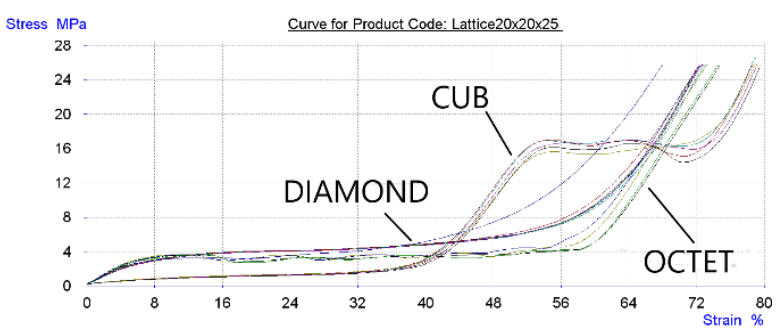

c.Performance lattices with $5 \mathrm{~mm}$ cellular length

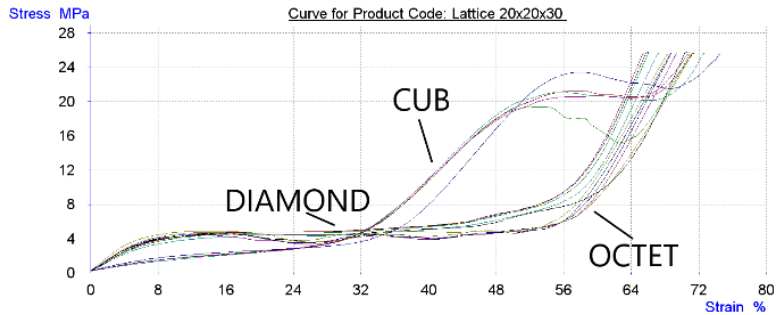

b.Top-Quality lattices with $10 \mathrm{~mm}$ cellular length

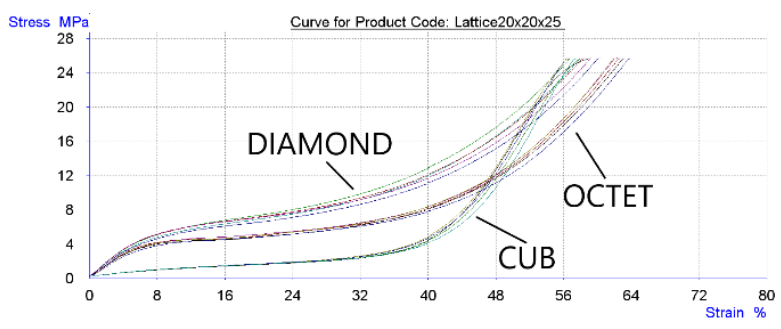

d.Top-Quality lattices with $5 \mathrm{~mm}$ cellular length

Figure 5. Behavior at $10 \mathrm{kN}$ compression force for diamond, cube and octet lattice structures

It has been demonstrated that the building orientation affects the elasticity proprieties of the structures. In Figure. 5.d it can be observed how the Cube structures, manufactured with a smaller layer thickness and a different building orientation than the other specimens, have a smaller plateau length, which could mean a better elastic behaviour. This observation will be researched in the future.

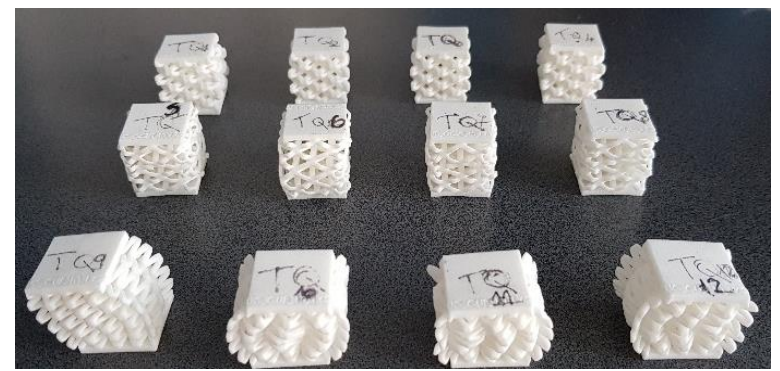

Figure 6. Tested specimens

\section{Conclusions}

The experiment approaches the compression testing of lattice structures manufactured by SLS from a polyamide plastic. Experimental conditions were taken into account as follows: design of the cellular unit, key elements regarding the dimensions and porosity, and parameters regarding the manufacturing process, as thickness of the printing layer and the building orientation.

There have been chosen 3 different geometries: diamond, octet and cube. Based on previous research made on similar structures manufactured of $\mathrm{CoCr}$ with the same technique, several premises have been noted. At least 5 specimens for each topology were manufactured, following the essential criteria for the plastics and compressing international standards. Each specimen was measured according to the international standards.
The compression tests were conducted on a universal testing machine, with a maximum of $10 \mathrm{kN}$ load cell. The Young's Modulus and the displacement at the maximum force were measured and used to determine the elastic characteristics.

It was observed and concluded that:

- For both the printing profiles, the specimens exhibit similar compressive mode;

- The curve behaviour is similar for diamond and octet structures;

- For the cube structures, there has been reported a stiffer behaviour;

- The building orientation affects the elasticity;

- The strut numbers, the porosity and their orientation inside the cellular unit are affecting the elastic properties.

- For the same PA2200 material, the TQ processed structures have slightly better elastic properties than the $\mathrm{P}$ ones;

- For the TQ specimens, the dimensions build in the $\mathrm{Z}$ direction are bigger that the $\mathrm{P}$ specimens.

The experiments show how dynamic is the additive manufacturing technology, how versatile it is for different applications, what difficulties can encounter and how it proposes solutions in unexpected ways.

\section{Acknowledgements}

This work was supported by 2 grants of the Romanian Ministry of Research\&Innovation, CCCDI UEFISCDI: PN-III-P1-1.2-PCCDI-20170224/ctr.number 7PCCDI/2018 - DigiTech, within PNCDI III, and PN $1924 \quad 05 \quad 02 / c t r$. number $17 \mathrm{~N} / 7.02 .2019$ - Rehabilitation and assistance of people with locomotor deficiencies with the help of integrated intelligent biomechatronic systems. 


\section{References}

[1] D. King, T, Tasey, Rapid tooling selective laser sintering injection tooling, Journal of Materials Processing Technology, 132, (2003), 42-48;

[2] C. Lancea, I. Campbell, L.A. Chicos, S.M. Zaharia, Compressive Behavior of Lattice Structures

[3] Manufactured by Polyjet Technologies, Polymers, 12, (2020), doi:10.3390/polym12122767;

[4] A.Mazzoli, Selective laser sintering in biomedical engineering, Med.Biol. Eng. COmput 51, (2013), 245-256,

[5] J. Parthasarathy, B. Starly, S.Raman, A design for the additive manufacture of functionally graded porous structures with tailored mechanical properties for biomedical applications, Journal of Manufactuyring Processes, (2011), 13, 160-170

[6] V. Shishkovsky, L. T. Volova, M. V. Kuznetsov, et.ad., Porous biocompatible implants and tissue scaffolds synthesized by selective laser sintering from Ti and NiTi, Journal of Materials Chemistry, (2008),

[7] C. Cosma, J. Kessler, A. Gebhardt, et. al.: Improving the Mechanical Strength of Dental Applications and Lattice Structures SLM Processed, Materials, (13), 905, (2020).

[8] C. Cosma, I. Drstvensek, P. Berce, et. al.: PhysicalMechanical Characteristics and Microstructure of Ti6Al7Nb Lattice Structures Manufactured by Selective Laser Melting., Materials , (2020)

[9] P. Berce, A. Sadeh, R. Păcurar, C. Miron-Borzan, Rapid product development using additive manufacturing technologies, Ro. J. Techn. Sci. Appl. Mechanics, (2019), Vol. 64, $\mathrm{N}^{\circ}$ 3, P. 189-207;

[10] Serap Gümüs, Juergen M. Lackner, Şeyda Polat, Bayram5, Wolfgang Kraschitzer, Hermann Hanning, Alperen Mesut Kaya, Metin Çallı5, and Attila Alkan, Failure behavior of PA12 based SLS lattice structure with macro-porosity, MATEC Web of Conferences 188, 03007 (2018),
ICEAF-V 2018,

https://doi.org/10.1051/matecconf/201818803 $\underline{007}$

[11] Mahshid, R.; Hansen, H.N.; Højbjerre, K.L., Strength analysis and modeling of cellular lattice structuresmanufactured using selective laser melting for tooling applications.Mater. Des.2016,104, 276-283.

[12] Mark Helou, Supachai Vongbunyong, Sami Kara, Finite Element Analysis and Validation of Cellular Structures, Procedia of the 26th CIRP Design Conference (2016), pp. 94 - 99

[13] Lancea, C., Chicos, L.A., Zaharia, S.M., Pop, M.A., Microstructure and micro-hardness analyses of titaniumalloy Ti6Al4V parts manufactured by selective laser melting, MATEC Web Conf. 2017, Vol. 94, article no. 3009, Doi: https://doi.org/10.1051/matecconf/201794030 $\underline{09}$

[14] J. Parthasarathy, B. Starly, S. Raman: A design for the additive manufacture of functionally graded porous structures with tailored mechanical properties for biomedical applications, Journal of Manufacturing Processes, vol. 13, Iss. 2, pp. 160-170, doi: 10.1016/j.jmapro.2011.01.004, (2011).

[15] L. Shamieh-Dinca, N. Popa, N. Milodin, D. Gheorghiu, S. Comsa: Influence of the process parameters on mechanical properties of the final parts obtained by selective laser sintering from PA2200 powder, MATEC Web of Conferences, vol. 299, pp. 11, (2019).

[16] L. Shamieh-Dinca, N. Popa, N. Milodin, D. Gheorghiu, S. Comsa: The importance of optimization of lattice structures for biomedical applications, Nonconventional Technologies Review, 23, 3, (2019). 